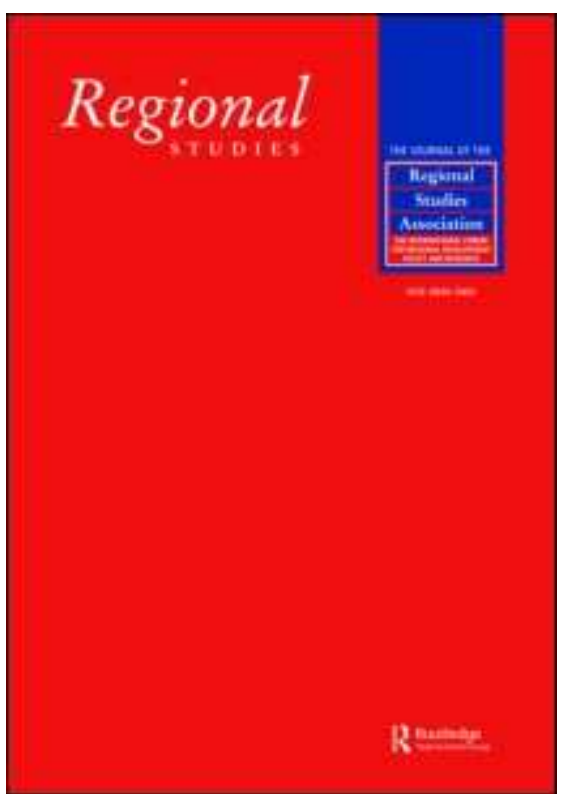

THE SPATIAL DISTRIBUTION OF PERSONAL INSOLVENCIES IN ENGLAND AND WALES 2000-2007

\begin{tabular}{|r|l|}
\hline Journal: & Regional Studies \\
\hline Manuscript ID: & CRES-2010-0159.R1 \\
\hline Manuscript Type: & Main Section \\
\hline JEL codes: & $\begin{array}{l}\text { R12 - Size and Spatial Distributions of Regional Economic Activity }< \\
\text { Economics, R11 - Regional Economic Activity: Growth, } \\
\text { Development, and Changes < R1 - General Regional Economics < R } \\
\text { - Urban, Rural, and Regional Economics }\end{array}$ \\
\hline Keywords: & $\begin{array}{l}\text { Personal Insolvency, Inequality, Mobility, Exploratory Data Analysis, } \\
\text { England and Wales }\end{array}$ \\
\hline
\end{tabular}

\title{
SCHOLARONE" Manuscripts
}




\section{THE SPATIAL DISTRIBUTION OF PERSONAL INSOLVENCIES IN ENGLAND AND}

WALES 2000-2007

\section{PAUL BISHOP}

Paul Bishop,

Professor of Economics,

Plymouth Business School,

University of Plymouth,

Devon, UK.

PL4 8AA.

E-mail: paul.bishop@plymouth.ac.uk.

(Received July 2009: in revised form March 2011) 


\begin{abstract}
This paper analyses the evolving spatial distribution of personal insolvencies across England and Wales from 2000-2007 utilising a range of exploratory techniques including inequality measures, spatial autocorrelation, Markov chains and mobility indices. The analysis reveals an intricate pattern of spatial clustering, fragmentation, persistence and mobility. Whilst average insolvency rates have increased, levels of spatial inequality have fallen implying a degree of convergence. However, there is considerable mobility of areas within the distribution. A widespread and growing spatial cluster of high insolvency rate areas is located across South West England and a shrinking cluster with low rates is centred in London.
\end{abstract}

Keywords: Personal Insolvency, Inequality, Mobility, Exploratory Data Analysis, England and Wales.

JEL: R11, R12 


\title{
INTRODUCTION
}

Personal insolvency is an issue that has attracted considerable attention since the onset of the recent financial crisis. Indeed, soaring levels of personal debt fuelled by excessive lending have been frequently blamed as a major cause of the crisis (HARTLEY, 2008). However, high levels of personal insolvency are not a new phenomenon. Personal insolvency rates have been rising rapidly since the mid-1980s in many countries including the USA, Canada, Australia, Germany and the UK (LI, 2007; CREDITREFORM, 2008). A variety of explanations have been offered including lenient insolvency laws, a falling stigma associated with bankruptcy, demographic factors and economic variables including rising debt to income ratios (ZYWICKI, 2005). Whilst no overall consensus has emerged concerning the relative importance of these factors, considerable empirical research has been generated, typically utilising US data. As a consequence, there is a growing recognition that insolvencies have an important spatial dimension (e.g. FISHER, 2005; EDMISTON, 2005). BROWN (1998), for example, concludes that there have been significant and persistent differences across US states since the early 1970s and attributes at least half of these variations to statespecific effects.

\begin{abstract}
Although there is considerable evidence available concerning spatial variations in US insolvencies, information on other countries is sparse. In the UK, this reflects a lack of data at the spatial level. However, since 2000, The Insolvency Service of England and Wales has collected data at a sub-regional level and this now permits an examination of spatial issues. Such an analysis is timely within the context of the current economic crisis and is also of academic and policy interest as insolvencies may be an important indicator of economic
\end{abstract}


problems within a region. For example, whilst existing empirical studies are far from conclusive, there is some evidence that high regional insolvency rates are associated with low incomes, high levels of debt and adverse events such as unemployment, divorce and medical problems (BISHOP AND GRIPAIOS, 2010). Another motivation for examining insolvency is that, as many insolvents are self-employed, insolvencies may be an indicator of failing entrepreneurship. A recent survey by the UK Federation of Small Businesses, for example, indicated that $21 \%$ of its members were increasing their risk of personal insolvency by relying on personal credit cards to finance their businesses due to lack of access to other finance (GRIBBEN, 2010). Of course, insolvency is not inevitably an entirely negative phenomenon, as it may be an outcome of desirable risk-taking activity. Thus, local economies in which entrepreneurial risk-taking is prevalent, might expect high levels of insolvencies as some ventures fail. However, insolvency has an adverse impact on an individual's credit rating, thereby reducing the ability to raise finance to acquire assets or start new ventures. Insolvency tends to be a lagging indicator, reaching a peak eighteen months to three years after the formal end of a recession and, consequently, current regional variations in insolvency may have a long term impact (R3, 2010). Thus, an understanding of spatial patterns in insolvency is of considerable importance in examining current and future patterns of regional growth.

This paper utilises Exploratory Spatial Data Analysis (ESDA) techniques to examine the spatial distribution of insolvencies in EW from 2000-2007. The focus is on EW as Scotland has a separate legal system governing insolvency. The ESDA approach has been used extensively to examine regional data in recent years (PATACCHINI and RICE, 2007, DALL'ERBA, 2005, LE GALLO and ERTUR, 2003). As ANSELIN (1993) notes, ESDA approaches the data without preconceived ideas or hypotheses and is, consequently, 


\section{BACKGROUND}

If an individual is unable to pay his/her debts, there are currently four main routes available in EW. First, the individual may attempt to negotiate an informal arrangement with creditors, perhaps agreeing to reschedule debt payments over a longer period of time. Second, an individual may petition for bankruptcy. Under this procedure, the individual's assets are available for distribution to creditors, apart from a few exemptions encompassing tools of trade and items necessary for the basic needs of the debtor and their family (WALTERS, 2004). After a certain period of time, most debts are discharged and the individual may make a fresh start free from discharged debts. The third option is an Individual Voluntary Arrangement (IVA), under which an individual reaches a legal arrangement with creditors to pay off a proportion of debt over a specified time period and is not forced to liquidate assets. 
A fourth method, the Debt Relief Order, was introduced in 2009; however, these were not in force during the period covered by the current study and are not further discussed.

Figure 1 depicts the dramatic growth in personal insolvencies involving bankruptcy or IVAs since the mid-1980s (no comparable data are available on informal arrangements). In 1987 there were only 7,400 personal insolvencies but by 2008 these had grown to 106,500 - a fourteen-fold increase. After a slow start, there has been a significant increase in IVAs which now constitute almost $40 \%$ of total insolvencies. The levelling off of the number of insolvencies towards the end of the series is attributable to a fall in IVAs. This may reflect a dispute between banks and insolvency practitioners concerning the charges for setting up IVAs, which resulted in banks adopting a stricter approach. However, a new code of conduct has now been agreed and the number of IVAs has grown since 2008, perhaps reflecting the evidence that IVAs offer a better return to creditors than bankruptcy (POND, 2002).

\section{Figure 1 approx here}

Research concerning the spatial distribution of insolvencies in EW is fairly limited, as statistics at the sub-regional level have only recently been officially published (July 2009). For EW, a regional analysis of 2006 data provides tentative evidence of an uneven spatial distribution (BISHOP and GRIPAIOS, 2010). In particular, the study finds three sub-regional clusters: one characterised by high insolvency rates (in the South West) and two (in Wales and the North West) characterised by low insolvency rates. However, the analysis is limited to one year and it is unclear whether these clusters are of long term significance. There have also been several studies of US regions. BROWN (1998), for example, shows that the ranking of insolvency rates across US states has been stable over time implying the existence of long term spatial effects. There is also evidence of spatial autocorrelation from a study by 


\section{DATA AND METHOD}

The data examined in this paper refer to the 376 Unitary and District Local Authorities in EW for 2000-2007. It is important to note that The Insolvency Service regard these data as experimental. The major quality issue concerns missing postcodes for some insolvents, particularly in the earlier years of the dataset. Thus, in 2000 , over $12 \%$ of postcodes were missing and these insolvencies could not be allocated to a sub-region. However, this had declined to under $4 \%$ by 2007 . There is no reason to suspect regional bias in the missing data and it is unlikely to affect the spatial analysis which is the main focus of the paper. However, the missing data may impact on time series analysis as the true rise in regional insolvencies will be overestimated given that part of the increase is attributable to improved data quality. To examine this issue an adjusted data series was calculated on the assumption that the missing data is spread pro-rata across sub-regions. The series is presented in the next section but reveals no substantive differences in the conclusions that can be drawn compared to the unadjusted series; consequently, the latter is primarily utilised for the subsequent analysis. 
The paper's methodology involves a set of ESDA techniques that describe spatial distributions, identify patterns of spatial association and examine mobility and change within distributions (GEZICI and HEWINGS, 2007). The focus is on identifying clusters, outliers and dynamic changes rather than the behaviour of the representative region as in confirmatory analyses (MAGRINI, 2004). Exploratory analysis is particularly pertinent to explore a new dataset and in cases where there is limited availability of time series information. ESDA techniques have been extensively utilised in recent years. In the case of Great Britain, for example, PATACCHINI and RICE (2007), use these techniques to examine regional economic performance and identify regional clusters. Similarly, BISHOP and GRIPAIOS (2005) examine the pattern of GDP per head across GB counties finding a complex pattern in the distribution that would be difficult to elucidate without the use of ESDA.

From a theoretical perspective, ESDA techniques might also be justified by the approach of DUNFORD (2003) based on a synthesis of a number of recent developments in economic geography. This approach argues that centrifugal forces driving convergence across space coexist with centripetal forces promoting divergence. The former forces reflect the outcome of a competitive process in which firms seek to emulate current market leaders, whilst the latter reflect a process of differentiation as firms seek new sources of competitive advantage. The balance of these forces differs across time and space resulting in complex patterns of relative economic performance, mobility and change. From this perspective, BISHOP and GRIPAIOS (2005) conclude that it is of limited relevance to concentrate purely on the issue of overall economic convergence or divergence. Of far more interest, is an examination of the complex processes of persistence, divergence and mobility within the spatial distribution. 
Initial analysis focuses on global inequality prior to a detailed examination of spatial issues. In all subsequent discussion, the insolvency rate is expressed as a percentage per thousand members of the local working population. Table 1 provides descriptive statistics (mean $(\mu)$, mean adjusted for the missing data $(\mu(\operatorname{adj}))$, standard deviation $(\sigma)$ and coefficient of variation $(\mathrm{CV})$ ) for the average insolvency rate across sub-regions and a breakdown by bankruptcies and IVAs. Figure 2 identifies a modest increase in the insolvency rate in the early 2000s, followed by a significant rise in the mid-part of the decade with a slight levelling off in 2006-7. The mean insolvency rate has risen 3.8 times over the period on the basis of the unadjusted data whilst bankruptcies have tripled and IVAs have risen by almost six times. Thus, although bankruptcies remain the most important component of total insolvencies, the contribution of IVAs has risen significantly. Adjusting the data slightly reduces the increase in the mean insolvency rate but has no impact on the substance of the conclusions.

\section{Table 1 and Figure 2 approx here}

As far as dispersion is concerned, $\sigma$ increases over time for all three measures; however, given the large increase in the means, a preferable measure is the CV which normalises $\sigma$ by $\mu$. The $\mathrm{CV}$, which is often used as a measure of $\sigma$ convergence, shows some evidence of decline for all three indices and provides initial evidence of a reduction in spatial inequality. However, although the CV is a widely used measure, there are many alternatives available and these may yield differing conclusions (LITCHFIELD, 1999). Consequently, as FAN AND SUN (2008) note, a commonly accepted practice is to use a variety of measures and compare the results. If the results are consistent across the indices, this adds confidence in the robustness of the results. 
One approach to defining inequality is to posit plausible axioms and examine measures which comply with these axioms. COWELL (1995) has shown that any inequality measure satisfying five commonly accepted axioms is a member of the Generalised Entropy (GE) class. The five standard axioms are: Anonymity (inequality is independent of any characteristic other than the indicator whose distribution is measured); the Pigou-Dalton principle (a mean-preserving progressive transfer reduces inequality); scale invariance (the inequality measure is invariant to uniform proportional changes); replication invariance (the inequality measure is invariant to replications of the population); decomposability (overall inequality is related consistently to constituent parts of the distribution such as population sub-groups). The formula for the GE class is:

$$
I(\alpha)=\frac{1}{\propto(\alpha-1) n} \sum_{j}\left[\left(\frac{l_{j}}{I}\right)^{\alpha}-1\right]
$$

In the current study, $n$ is the number of sub-regions, ${ }_{j}$ the insolvency rate for the $j$ th subregion, $\bar{I}$ is the mean insolvency rate, whilst $\propto$ is a parameter representing the weight given to differences in insolvency rates at various parts of the distribution. In principle, $\propto$ may take any value but is typically set equal to 0,1 or 2 . For a value of 0 , the index gives more weight to distances between values in the lower tail and, using l'Hopital's rule, takes the form of the Mean Log Deviation; $\boldsymbol{\alpha}=\mathbf{1}$ gives the Theil (T) measure which applies equal values to all differences, whereas $\alpha=2$ yields the squared coefficient of variation and more weight is given to differences in the upper tail. Calculation of these three indices for 2000-2007 revealed almost identical measures of inequality, implying that inequality is insensitive to $\propto$ 
and lending confidence to the robustness of the measure. Consequently, the analysis only reports the value of $\mathrm{T}$ (which varies from zero to an upper limit of $\ln (n)$ ). $\mathrm{T}$ is defined as:

$$
T=\frac{1}{n} \sum_{j} \frac{I_{j}}{I} \ln \left(\frac{l_{j}}{I}\right)
$$

The later analysis of mobility makes use of the Gini Correlation Coefficient, which is related to the widely used Gini $(G)$ inequality measure. Consequently, although $G$ lies outside the entropy family, it is introduced as a further measure. As inequality increases, $\mathrm{G}$ varies from 0 to 1 and it may be expressed as:

$$
G=\frac{1}{2 n^{2} \bar{I}} \sum_{j} \sum_{k}\left|I_{I}-I_{K}\right|
$$

It is also possible to calculate population-weighted variations of the indices. However, these proved to be extremely close in value to the unweighted indices and made no substantive difference to the conclusions. Consequently, to avoid excessive output, the analysis concentrates on the unweighted indices.

Table 2 presents a summary of the $\mathrm{T}$ and $\mathrm{G}$ indices for inequality in insolvency rates. In general, the size of both indices indicates relatively modest levels of inequality. Average inequality is somewhat less than that typically found in previous studies of UK income 
inequality. For example, $\mathrm{G}$ varies from 0.137 to 0.206 which is slightly lower than similar income measures calculated for the UK. According to SMITH (2008), the UK G index of income inequality was approximately 0.34 in 2005, whilst DICKEY'S (2001) study of GB earnings inequality calculates that $G$ varied from 0.241 to 0.305 from 1975-1995. Normalising $\mathrm{T}$ in Table 2 relative to its maximum value facilitates a comparison with DICKEY's (2001) index and also reveals a lower level of inequality in the insolvency data.

\section{Table 2 approx here}

As far as trends in inequality are concerned, the $\mathrm{T}$ and $\mathrm{G}$ indices imply a consistent pattern involving a small increase from 2000-2001 followed by a steady fall through to 2006 and then a levelling off in 2007. Average inequality has fallen over the period as a whole by $43 \%$ for $\mathrm{T}$ and $28 \%$ for $\mathrm{G}$ and the fall is statistically significant for both indices. Whilst the relatively short time period precludes any firm conclusions concerning long run trends, the extent of the fall is substantial. It suggests that the recent rise in insolvencies has occurred primarily in areas that previously had low insolvency rates, thereby reducing inequality and implying a degree of convergence across sub-regions. This hypothesis is reinforced by a significantly negative correlation coefficient $(-0.665$, significant at the $0.01 \%$ level) between the sub-regional insolvency rate in 2000 and the growth rate of insolvencies through to 2007 .

\section{REGIONAL INEQUALITY AND CLUSTERING}

Global measures assess average inequality across the whole sample and it is possible that this masks variations at the local level. Consequently, it is useful to decompose the global indices into component groups such as the ten standard regions of EW. G can be decomposed in a variety of ways; however, as LITCHFIELD (1999) notes, these methods do not typically 
result in intuitively appealing components, yielding a residual term which is difficult to interpret (DICKEY, 2001). One advantage of entropy indices is their easy decomposability into intuitively appealing component groups without a residual. If there are $g$ regions, $\mathrm{T}$ can be decomposed as:

$$
T=\sum_{g} p_{g} \mu_{g} T_{g}+\sum_{g} p_{g} \mu_{g} \ln \left(\mu_{g}\right)
$$

$p_{g}, \mu_{g}$ and $T_{g}$ are respectively the population share, regional mean insolvency rate relative to the overall mean and $\mathrm{T}$ index for region $g$. The first term represents the within-region (intraregional) inequality component and the second the between-region (inter-regional) component. Using this decomposition, it is possible to assess the extent to which total inequality is affected by inequality within individual regions as compared to inequality between regions.

\section{Table 3 approx here}

Table 3 presents the decomposition results and shows that the intra-regional component dominates, varying from $67-82 \%$ of total inequality implying that inequality within regions is more important than that across regions. This result is broadly similar to DICKEY's (2001) decomposition of GB earnings inequality, which finds that within group inequality accounts for up to $95 \%$ of total inequality from 1975-95. One obvious explanation is that standard regions are administrative rather than economic constructs and are extremely heterogeneous in their economic make-up. The South West, for example, ranges from the peripheral and relatively low income areas of the far South West through the M4 corridor to high income areas closer to London. A variety of other regional decompositions were also investigated (e.g. based on OECD measures of rurality) but similar conclusions emerged, implying that 
any spatial pattern of insolvencies is more complex than broad regional breakdowns can capture. An indication of this is seen in Figures 3 and 4 which present maps of insolvency rate quartiles across sub-regions for 2000 and 2007. There are obvious spatial variations with some evidence of regional clusters of high insolvency rates particularly across parts of the South West and East Midlands and a low rate cluster in the south centred on London. However, these clusters clearly do not conform to standard regional boundaries.

\section{Figures 3 and 4 approx here}

To further examine the issue of clustering, it is instructive to calculate spatial autocorrelation statistics. Spatial autocorrelation exists if the distribution of insolvencies is non-random across space: positive spatial autocorrelation implies the coincidence of similar insolvency rates in neighbouring locations whilst negative autocorrelation implies that an area is surrounded by neighbours with dissimilar values. Global autocorrelation can be assessed by Moran statistics which examine average levels of autocorrelation across all observations. The Moran statistic can be defined as:

$$
I=\left(\frac{n}{S}\right) \frac{\sum_{i} \Sigma_{j} w_{i j} z_{i} z_{j}}{\sum_{i} z_{i}^{2}}
$$

$n$ is the number of observations; $z_{i}$ is the deviation of the value of the variable in the $i$ th location from the mean; $w_{i j}$ is the weight (in the case of first order contiguity it equals 1 if areas are adjacent and 0 otherwise); $s=\sum_{i} \sum_{j} w_{i j}$. To examine the contribution of individual locations, $I$ can be decomposed into local indicators (LISA statistics) which can be defined for the $i$ th location as $\boldsymbol{I}_{i}=z_{i} \sum_{i} w_{i j} z_{j}$, where the observations are standardised (mean 0 and variance 1). A LISA statistic may be computed for every observed location and 
measures the extent of significant spatial clustering of similar values of a variable in neighbouring regions. Thus, positive local autocorrelation may be present if, for example, an area with a high rate of insolvency has neighbours which also exhibit high level of insolvency. This facilitates the identification of wider clusters of regions with similarly significant LISA statistics (ANSELIN, 2003). These may constitute clusters in which a group of neighbouring sub-regions with high insolvency rates (and significant LISA statistics) are located adjacent to other sub-regions with high insolvency rates (high-high) or clusters in which areas with low insolvency rates are located adjacent to other sub-regions with low insolvency rates (low-low). It is also possible to identify spatial outliers which exhibit negative spatial autocorrelation (i.e. low-high or high-low values). Moran and LISA statistics were calculated utilising a contiguity based binary weight matrix to define neighbouring regions (adjacent areas were coded as 1 and non-adjacent areas 0 ).

Table 4 presents the Moran statistics for 2000-2007. Significance against a null of no spatial autocorrelation was tested using a permutation approach in which a reference distribution is generated for random layouts with the same data values as those observed (ANSELIN, 2003). The mean and standard deviation of the reference distributions are detailed in the table. All the Moran statistics are highly significant (at the 0.0010 level using 999 permutations). Thus, there is strong evidence of positive global spatial autocorrelation: insolvencies do not appear to be randomly distributed across sub-regions.

\section{Table 4 approx here}

Computing LISA statistics generates a huge volume of output (one statistic for every area per year) and, consequently, these are most easily presented via cluster maps which show all locations with significant LISA statistics by type of association. Figures 5 and 6 present 
illustrative significance maps using a $0.05 \%$ level of significance for 2000 and 2007. In 2000 there are four sizeable regional clusters of areas with similarly significant LISA statistics: three clusters of high-high sub-regions across far South West England, parts of North West England and the East Midlands and a fourth low-low cluster centred on London. A much smaller high-high cluster may also exist in the North East centred on Tyneside. The 2007 map presents a different picture: a South West cluster is still evident and is larger in size; the London, East Midland and North East clusters have shrunk, whilst a North West cluster still exists but is centred on different areas than the original cluster. Clearly, this raises questions about the stability of the potential clusters.

\section{Figures 5 and 6 approx here}

An examination of LISA statistics for all years indicates that the South West cluster is highly stable appearing every year with a pattern of expansion from the far South West to adjacent areas. The cluster has a number of core members (in terms of significant LISA statistics): these include five sub-regions that are members in all eight years (West Devon, Teignbridge, South Hams, Restormel and Caradon), five which are members for seven years (Torridge, North Cornwall, Mid Devon, Kerrier, East Devon) and two that are members for six years (Plymouth and Torbay). All these areas are located within the two far South West counties of Devon and Cornwall. Interestingly, there are several areas (Taunton Deane, South Somerset, Sedgemoor, North Devon and Carrick) which were outside the cluster in 2000 but joined for four or more consecutive years towards the end of the series. This suggests that the cluster is expanding geographically into more northern areas of the region thereby forming a larger cluster characterised by high insolvency rates. 
Whilst further research is required to explain the far South West cluster, BISHOP and GRIPAIOS (2010) provide tentative evidence (based on 2006 data) that the high rate of insolvency may be associated with relatively low earnings, making individuals in the region vulnerable to adverse events. This is certainly plausible over the time period covered by the present study as low earnings are a long term regional phenomenon: for example, from 20022007 median gross earnings were $82 \%$ of the EW average in Cornwall and in $86 \%$ in Devon. A second factor that may affect insolvency is the relatively high level of armed forces personnel in the region. Armed forces personnel often face significant problems in adjusting to civilian life, resulting in high levels of homelessness, convictions and financial distress (NAPO, 2008). The extent of these problems is highlighted by the government's recent announcement of a new system of grants and loans specifically to assist ex-armed forces personnel with training and business start-ups (SMALLBUSINESS.CO.UK, 2010). Moreover, these issues are not unique to EW; for example, in the US special dispensations for low-income veterans were inserted into the 2005 Bankruptcy Act due to these concerns (GORDON, 2005). Finally, another factor that might account for the persistent cluster is the coastal nature of much of the region. A recent report, for example, notes that coastal conurbations have insolvency rates one third higher than the national average (BUTTERWORTH and HOWE, 2009). Many coastal areas in the far South West have large tourism sectors, which have strong seasonal demand fluctuations, creating significant income uncertainty, thereby influencing insolvency rates.

The London-centred cluster exists in all years but tends to wax and wane in size. It has a strong core in Greater London with 22 sub-regions remaining members of the cluster for six or more years. However, several adjacent regions outside London appear to leave the cluster in later years suggesting that it is reducing in size. The relatively low rates of insolvency may 
be partly explained by levels of earnings well above the national average which makes it easier to withstand adverse events, and possibly a "capital city" effect which provides a climate suited to entrepreneurship and access to finance. Elsewhere, the initial North West cluster vanishes by 2003 and is replaced from 2005-2007 by a more northern cluster whilst the East Midlands cluster largely vanishes after 2003. There is no evidence of a long term north-eastern cluster extending beyond the narrow confines of Tyneside. Finally, it is also worth noting that a small number of areas are consistent outliers in the sense that they exhibit negative spatial autocorrelation. Whilst there is no obvious spatial pattern, four of these areas are relatively peripheral coastal locations (or islands), perhaps with self-contained local economies that differ significantly from adjacent areas (Pembrokeshire, Isle of Anglesey, Isle of Wight, Castle Morpeth)

\section{REGIONAL MOBILITY AND CHANGE}

The previous analysis reveals a complex pattern of inequality, with the changing nature of clusters suggesting movement within the distribution. A useful method with which to examine these issues is the distribution dynamics approach of QUAH (1993). This approach concentrates on analysing the movement of a cross-sectional distribution over time with particular emphasis on its shape and intra-distributional dynamics (MAGRINI, 2004). If $d_{t}$ denotes the distribution of insolvencies across regions at time $t$ and it is assumed that insolvencies follow a first order autoregressive process, then $d_{t+1}=P\left(d_{t}\right)$, where $P$ is an operator that maps the distribution from $t$ to $t+1$. If this is interpreted as a discrete process, the distribution may be divided into a finite number of states representing particular ranges of insolvency and $d_{t}$ denotes a vector of probabilities of being in state $j$ at time $t . P$ can be viewed as a transition probability matrix, $M$, which contains the transition probabilities of 
Implementation of the discrete approach requires dividing the data into classes. This is typically undertaken by partitioning the data into equal groups in the base year and then either holding the class boundaries constant over time, or allowing the boundaries to vary over time to maintain equal observations in every class (QUAH, 1993). In the second case, the ergodic distribution is uniform but the time-varying probabilities for transition periods can be averaged to estimate the transition probability matrix. Whichever approach is taken, the discrete approach has the disadvantage that the choice of the number of classes is somewhat arbitrary. An alternative is to use continuous stochastic kernels. This approach views the $P$ operator as mapping a continuum of insolvency rates at time $t$ into another continuum at time $t+1$ (QUAH, 1997). Whilst this method does not require partitioning, it largely relies on graphical method of interpretation and does not lend itself to the ease of interpretation and hypothesis testing of the discrete approach. Consequently, the paper follows the advice of SCHLUTER (1997) in using the continuous and discrete approaches as complementary methods and examining the sensitivity of the discrete conclusions to varying the number of states. 
Table 5 presents the transition probability matrix for an illustrative four discrete states and one year transitions with the boundaries held constant at their initial level and the insolvency rate normalised by the mean. A Likelihood Ratio test of the validity of the Markov model (COLLINS, 1975) with a null that the probability of ending in a class does not depend on the starting class is rejected at the $0.01 \%$ level implying that there is at least a first order Markov chain (chi-square $=256.0$ with 9 d.o.f.). Time homogeneity of the transition probabilities was examined by dividing the sample into sub-periods and testing whether the sub-period transition matrices differ from that produced from the entire sample (BICHENBACH and BODE, 2003). The results confirm acceptance of the null of equal probabilities (e.g. with two equal sub-samples chi-square $=5.15,12$ d.o.f.). The values along the diagonal represent levels of persistence: these are moderately high in the top and bottom states (i.e. the states with the highest and lowest insolvency rates) but lower in the intermediate categories. Thus, $71 \%$ of the sub-regions in the highest quartile and $65 \%$ in the lowest in period $t$ persist in $t+1$ compared to levels of below $50 \%$ for the intermediate categories. There is considerable movement between the inner two categories, implying a fair degree of churning within the distribution although a movement jump of more than one category is rare.

\section{Table 5 approx here}

The robustness of the conclusions to variations in the number of partitions was also examined. The ergodic distributions for the four to eight state cases are shown in Table 6 . The four state limiting distribution shows little movement from the initial uniform distribution (i.e. 0.25 in every category). Thus, although there is movement within the distribution, its overall shape remains fairly constant. This is broadly true when the number of initial states is expanded, although there is some evidence of a peak at the lower end of the distribution. The conclusions are also robust to choice of partitioning method. Table 7 , for example, shows the four fractile, time invariant transition probability matrix for one year 
transitions with varying boundaries to maintain classes with constant numbers. The matrix has very similar probabilities to the constant boundary approach. The upper boundaries have a relatively small variation and there is no obvious pattern in the movement of the boundaries over time.

\section{Tables 6 and 7 approx here}

For the continuous case, the pattern of transitions is most easily ascertained by examining the contour map of the stochastic kernel which provides a top down view of the probability mass. Figure 7 shows the map for one year transitions with low probability states ignored to facilitate interpretation. Convergence is implied if the mass is vertically distributed indicating a mapping of normalised insolvency rates in $t$ to a narrow band in $t+1$. However, the probability mass is largely located along the positive diagonal implying that rates in period $t$ tend to map into similar rates in $t+1$. This suggests a fair degree of persistence in the distribution. There is, however, some evidence of a slight twisting of the distribution towards the vertical, particularly at the extremes, providing some evidence that poor and low performers are moving closer to the average.

\section{Figure 7 approx here}

To examine the issue of intra-distributional change in more detail, it is useful to calculate mobility indices, which provide summary measures of the extent to which regions move within the distribution between time periods. For the discrete case, the standard Shorrocks Index (S) is utilised (QUAH, 1995). This has a lower bound of 0 and increases as mobility rises. As this index is based upon a probability matrix reflecting the particular number of groups used for the Markov analysis, it can be complemented by mobility indices based on the Gini Correlation Coefficient (GCC) which calculate mobility without the need for the division of the distribution into groups. (YITZHAKI and WODON, 2004). The GCC between 
insolvencies in period $t$ and insolvency ranks at time $t-1, R_{t-1}$, (both normalised relative to means) is defined as:

$$
G C C_{t, t-1}=\frac{\operatorname{cov}\left(I_{j t}, R_{j, t-l}\right)}{\operatorname{cov}\left(I_{I t}, R_{j, t}\right)}
$$

This is often termed a backwards-looking measure. However, it is also possible to change the direction of measurement and define a similar forwards-looking measure by exchanging the $t$ and $t-1$ subscripts or define a third symmetric measure as a weighted average of the two other measures. The present paper only presents the backwards-looking measure as the values of the other measures differed only marginally from the backwards measure. This paper follows YITZHAKI and WODON (2004) in defining the mobility index as $M_{t, t-1}=1-G C C_{t, t-1}$ ensuring that the index is positive and bounded between 0 and 2 . A value of $M_{t, t-1}=0$ indicates that there is no change in ranks and hence no mobility; a value of 2 implies a total reversal of ranks and hence perfectly perverse mobility, whilst a value of 1 implies that mobility is random (YITZHAKI and WODON, 2004).

Table 8 shows that $S$ rises in the early part of the period and reaches a peak in 2002-2003 before falling below its initial value. Over the whole period, there is a small decline in $\mathrm{S}$ but no significant difference between the measure for the first and final transition period. Thus, this measure provides no evidence of any significant change in the extent to which regions move within the rankings over the time period. The value of $M_{t, t-1}$ is small for all years, indicating little movement within the distribution. However, there is a statistically significant $30 \%$ fall in $M_{t, t-1}$ (the $95 \%$ confidence interval for the decrease of the index by 0.061 is 0.054-0.069 which excludes 0). This fall implies a lower degree of movement within the 
distribution in the latter part of the period. Taken together, the results imply that there is no evidence of an increase in mobility and $M_{t, t-1}$ provides possible evidence of a fall. This has important implications for long run inequality as it suggests that regional rankings are relatively persistent with only a limited (and perhaps falling) ability for regions to change their position within the rankings. Moreover, the varying picture to emerge from the two indices highlights the potential differences that can emerge from discrete and continuous approaches.

\section{Table 8 approx here}

To further understand patterns of persistence and mobility, sub-regions can be classified according to their position and movement within the distribution. Taking the four state case as illustrative, twenty-two sub-regions had persistently low insolvency rates in the sense of being located in the bottom quartile in all years. Fifteen of these were located in Greater London and most belonged to the London cluster identified by LISA statistics. This confirms a core set of neighbouring sub-regions in London characterised by persistently low levels of insolvency compared to other regions. At the other end of the distribution, twenty-three regions were persistently located in the highest quartile. Twelve of these were in the South West and most were members of the high-high South West cluster. Thus, a group of adjacently located areas in this region are clearly characterised by levels of insolvency that are persistently high. There is no obvious regional pattern that can be ascertained by examining the other sub-regions persistently at the top or bottom of the distribution. Indeed, there appear to be "islands" of areas with low and high insolvency rates spread throughout EW. 
The analysis of mobility also reveals a group of thirty sub-regions that started off (in both 2000 and 2001) in the lowest quartile but moved into a higher group by 2007 and remained in a higher group for at least the final three years of the time series. There is a distinct regional dimension to this grouping with thirteen located across the South East and a further seven in the Eastern region. This downward mobility (in terms of a rising relative insolvency rate) helps to explain the shrinking of the Southern cluster. Employing the same classification scheme at the other end of the distribution identified twenty-one sub-regions that were "upwardly mobile" and moved out of the lowest quartile. Again there was a distinct regional pattern with eight being located in the North West; however, the remainder were widely spread and no south-western area escaped the high insolvency group, emphasising the persistent nature of high insolvency rates in this sub-region.

\section{CONCLUSION}

This paper has used ESDA techniques to examine the distribution and evolution of personal insolvencies in England and Wales during 2000-2007. It makes a distinct contribution by providing the first detailed analysis of this newly available dataset and applying a wide range of exploratory techniques. It is clear that that there has been a significant increase in the mean sub-regional insolvency rate with a particular increase in the relative importance of IVAs. However, levels of inequality appear to have been falling, with many areas with previously low insolvency rates suffering substantial increases. Overall levels of inequality are lower than those typically found in studies of inequality concerning other regional performance indicators. 
One significant conclusion to emerge from the study is the identification of positive autocorrelation in regional insolvency rates and some evidence of regional clusters. In particular, there is a widespread cluster of areas with high insolvency rates in South West England and a cluster of areas with low insolvency rates in London. Mobility measures confirm the persistence of many areas within the South West cluster and some growth in the size of the cluster over time; however, there is some shrinkage in the London centred cluster. The ESDA approach of this paper does not facilitate firm explanations for the existence of these clusters. However, it is plausible that the South West cluster might be associated with low incomes, the presence of many ex-armed forces personnel and the coastal nature of much of the region, whilst the London cluster might be associated with high incomes and a capital city effect. Further detailed research is required to identify the process at work within these clusters.

Apart from the two major clusters, other clusters are smaller and more transient whilst there are a number of isolated areas bearing little similarity to their neighbours. Although there is some evidence of a degree of convergence in insolvency rates, the underlying picture is highly complex. Indeed, at the sub-regional level, there is an intricate pattern of clustering, fragmentation, persistence and mobility. This tends to support the view that solely focusing upon the issue of overall convergence or divergence risks oversimplifying the heterogeneity of the spatial economy. Thus, simply concluding that there is apparent convergence across the dataset would mask, for example, the existence of a persistent and geographically growing insolvency problem across much of the South West region. In theoretical terms, the patterns offer some support for DUNFORD'S (2002) view that the spatial economy is 
typically characterised by complex patterns of performance, mobility and change. The conclusions also echo BISHOP and GRIPAIOS' (2005) findings from the analysis of the spatial distribution of GDP per head, which finds a complex pattern of persistence, divergence and mobility. It also highlights the utility of the ESDA approach which seeks to identify and examine these complexities, rather than concentrate on the behaviour of the representative economy. However, having identified these patterns, further research is needed to examine whether the spatial patterns are of longer term significance and identify explanatory factors through confirmatory analysis.

The analysis of this paper is also important from a more general policy viewpoint, as it suggests that the standard regions of England and Wales are an inadequate basis on which to formulate policy. The poorly performing and persistent South West cluster, for example, is not coterminous with the standard South West region; similarly, the low insolvency cluster in the London area does not conform to any standard regional boundary, whilst elsewhere groups of neighbours with similar insolvency rates are contained within standard regions or lie across regional boundaries. Thus, policies designed to improve performance may need much tighter targeting than, for example, the broad regions covered by Regional Development Associations. 


\title{
REFERENCES
}

\author{
ANSELIN L. (2003) An Introduction to Spatial Autocorrelation Analysis with GeoDa, \\ Spatial Analysis Laboratory, University of Illinois, Urbana-Champaign.
}

\begin{abstract}
ANSELIN L. (1993) Exploratory Spatial Data Analysis and Geographic Information Systems, Research Paper 9329, Regional Research Institute, West Virginia University.
\end{abstract}

BICKENBACH F. and BODE E. (2003) Evaluating the Markov Property in Studies of Economic Convergence, International Regional Science Review 26, 363-392

BISHOP P. and GRIPAIOS P. (2010) Personal Insolvency in England and Wales: a Spatial Analysis, Urban Studies 47, 1687-1702.

\begin{abstract}
BISHOP P. and GRIPAIOS P. (2005) Patterns of Persistence and Mobility in GDP per head across GB Counties, TESG 96, 529-40.
\end{abstract}

BROWN R.A. (1998) Time Series Analysis of State-level Personal Bankruptcy Rates, 19701996, Bank Trends, (FDI Division of Insurance working paper 98-02), Washington D.C.

BUTTERWORTH M. and HOWE A. (2009) Britain's coastal towns have highest levels of bankruptcies, Telegraph.co.uk, 26 October, 
http://www.telegraph.co.uk/finance/personalfinance/6417257/Britains-coastal-towns-havehighest-level-of-bankruptcies.html

COLLINS L. (1975) An Introduction to Markov Chain Analysis. CATMOG 1, University of East Anglia, Norwich.

COWELL (1995) Measuring Inequality, $2^{\text {nd }}$ edition, Harvester Wheatsheaf, Hemel Hempstead.

$\begin{array}{llll}\text { CREDITREFORM (2008) Insolvencies in } & \text { Europe }\end{array}$ http://www.google.co.uk/search?hl=en\&q=INSOLVENCY+RATES+IN+EUROPE\&meta=

DALL'ERBA S. (2005) Distribution of regional income and regional funds in Europe 19891999: An exploratory spatial data analysis, Annals of Regional Science 39, 121-148

DICKEY H. (2001) Regional Earnings Inequality in Great Britain: A Decomposition Analysis, Regional Studies 35, 605-12.

DUNFORD M. (2003) Theorizing Regional Economic Performance and the Changing Territorial Division of Labour, Regional Studies 37, 839-854. 
EDMISTON K. D. (2005) New insights in the determinants of regional variation in personal bankruptcy filing rates, Community Affairs Research Working Paper, 2005-05, Federal Reserve Bank of Kansas City, Kansas City.

FAN C. AND SUN M. (2008) Regional Inequality in China, 1978-2006, Eurasian Geography and Economics 49, 1-20.

FAY S., HURST E. AND M. J. WHITE (2002) The Household Bankruptcy Decision, American Economic Review 92, 706-718.

FISHER J. D. (2005) The effect of unemployment benefits, welfare benefits and other income on personal bankruptcy, Contemporary Economic Policy 23, 483-92.

GEZICI F. and HEWINGS G. J. D. (2007) Spatial Analysis of Regional Inequalities in Turkey, European Planning Studies 15, 383-403.

GORDON M. (2005) Senate bill eases bankruptcy rules for military, Mail Tribune, March 2005, http://archive.mailtribune.com/archive/2005/0302/biz/stories/03biz.htm.

GRIBBEN R. (2010) Business owners opt for personal insolvency, Telegraph.co.uk, 1 Feb 2010, http://www.telegraph.co.uk/finance/yourbusiness/7130580/Business-owners-opt-forpersonal-insolvency.html. 
HARTLEY V. (2008) Consumer debt 'outstrips GDP', The Guardian, $22^{\text {nd }}$ August, Manchester, http://www.guardian.co.uk/money/2008/aug/22/debt.consumeraffairs.

LE GALLO J. and C. ERTUR (2003) Exploratory spatial data analysis of the distribution of regional per capita GDP in Europe, 1980-1995, Papers in Regional Science 82, 175-201.

LEFGREN L. and MCINTYRE F. (2009) Explaining the Puzzle of Cross-State Differences in Bankruptcy Rates, Journal of Law \& Economics 52, 367-393.

LI W. (2007) What Do We Know About Chapter 13 Personal Bankruptcy Filings? Business Review, Federal Reserve Bank of Philadelphia, Fourth Quarter, 19-26.

LITCHFIELD J.A. (1999) Inequality: Methods and Tools, World Bank, http://siteresources.worldbank.org/INTPGI/Resources/Inequality/litchfie.pdf.

MAGRINI S. (2004) Regional (Di) Convergence, in V. H. and J.F T. (Eds) Handbook of Regional and Urban Economics, pp. 2741-96. North-Holland, Amsterdam.

NAPO (2008) Ex-Armed Forces Personnel and the Criminal Justice System http://www.napo.org.uk/cgibin/dbman/db.cgi?db=default\&uid=default\&ID=187\&view_records=1\&ww=1

PATACCHINI E. and RICE P. (2007) Geography and economic performance: Exploratory Spatial Data Analysis for Great Britain, Regional Studies 41, 489-508. 
POND K. (2002) New Rules and New Roles for the Individual Voluntary Arrangement, Insolvency Law \& Practice 18, pp 9-13.

QUAH D. (1993) Empirical cross-section dynamics in economic growth, European Economic Review 37, 426-34.

QUAH D. (1995) Aggregate and Regional Disaggregate Fluctuations. Centre for Economic Performance, Discussion Paper no. 273, LSE, London.

QUAH D. (1997) Empirics for growth and distribution: polarization, stratification and convergence clubs, Journal of Economic Growth 2, 27-59.

R3 (2010) The "Insolvency lag": risks for 2010, Association of Business Recovery Professional Briefing Paper,

https://www.r3.org.uk/uploads/documents/Insolvency\%20Lag\%20Briefing\%20Paper\%2026. 01.2010.pdf

SCHLUTER C. (1997), On the Non-stationarity of German Income Mobility, Discussion Paper No. DARP/30, Toyota Centre. London: LSE. 
SMALLBUSINESS.CO.UK (2010) New start-up fund for ex-servicemen, Mar 172010

http://www.smallbusiness.co.uk/channels/small-business-finance/news/1206343/new-startupfund-for-exservicemen.thtml

SMITH J. (2008) The Gini Index: Measuring Income Distribution, Investopedia, http://www.investopedia.com/articles/economics/08/Gini-index.asp.

WALTERS A. (2004) Personal Insolvency Law After the Enterprise Act: An Appraisal, Insolvency Lawyers' Association Annual Conference, Paris, France.

YITZHAKI S. and WODON Q. (2004) Mobility, inequality and horizontal equity, Research in Economic Inequality 12, 177-98.

ZYWICKI T.J. (2005) An Economic Analysis of the Consumer Bankruptcy Crisis, Northwestern University Law Review 99, 1463-1541. 
Figure 1: Number of personal insolvencies in England and Wales, 1987- 2008

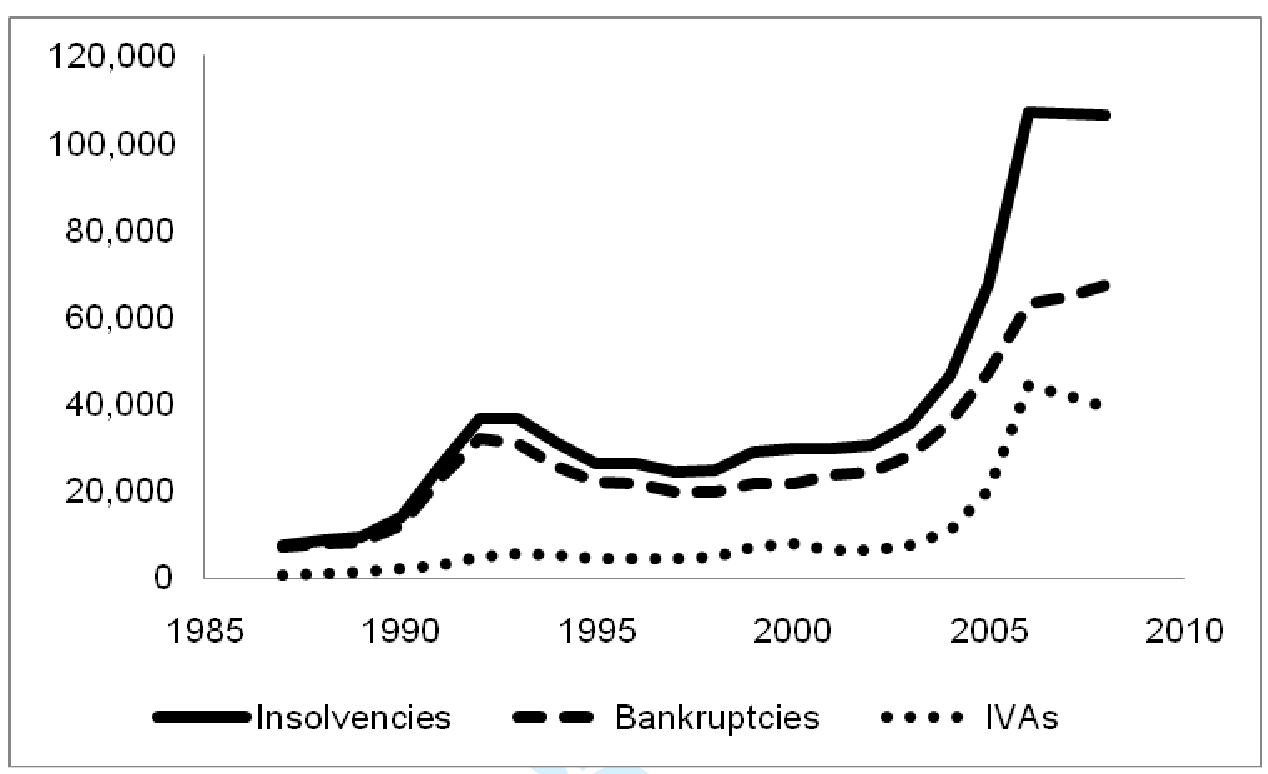


Figure 2: Trend in average sub-regional insolvency rates 2000-2007 (per '000 working population)

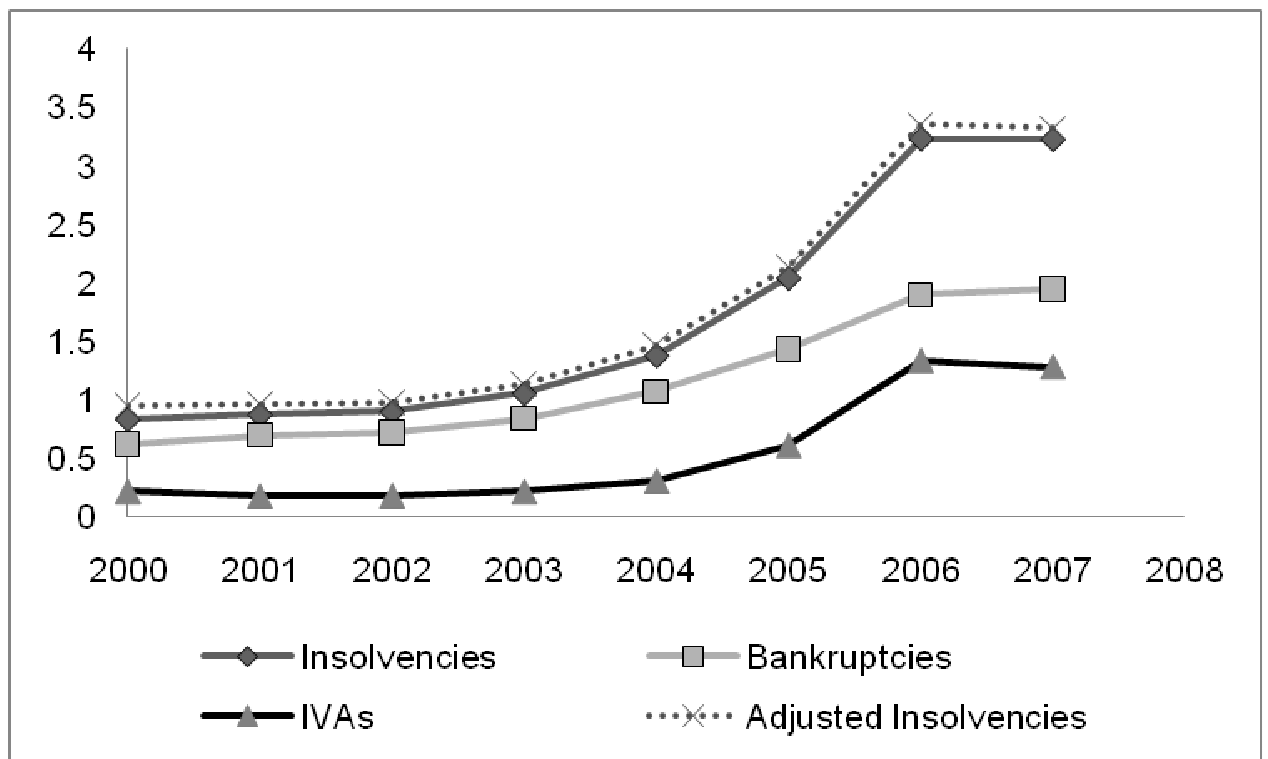


Figure 3: Insolvency quartiles 2000

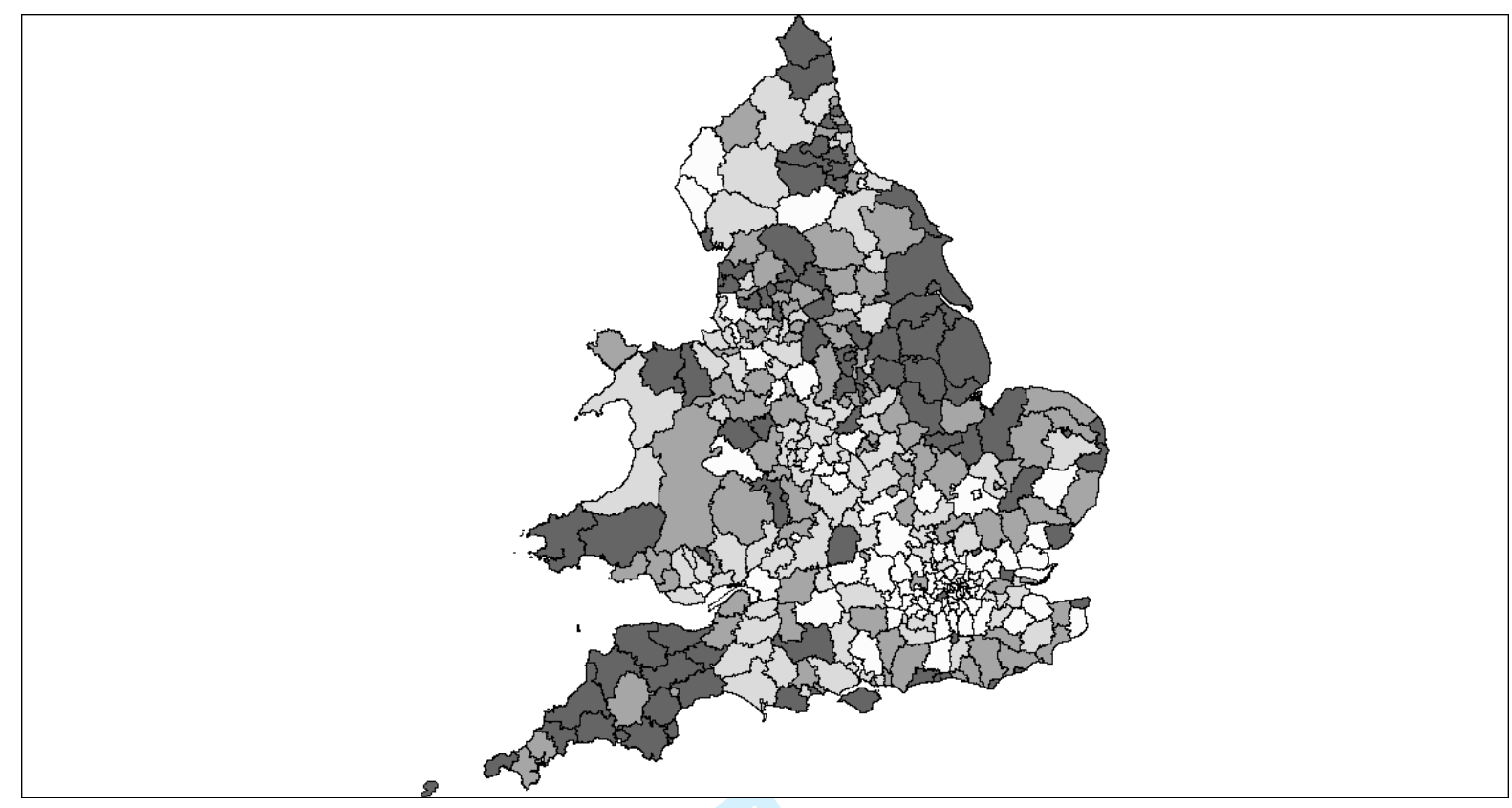

Note: The darkest shaded areas indicate the top quartile through to the lightest areas indicating the lowest quartile. 
Figure 4: Insolvency quartiles 2007

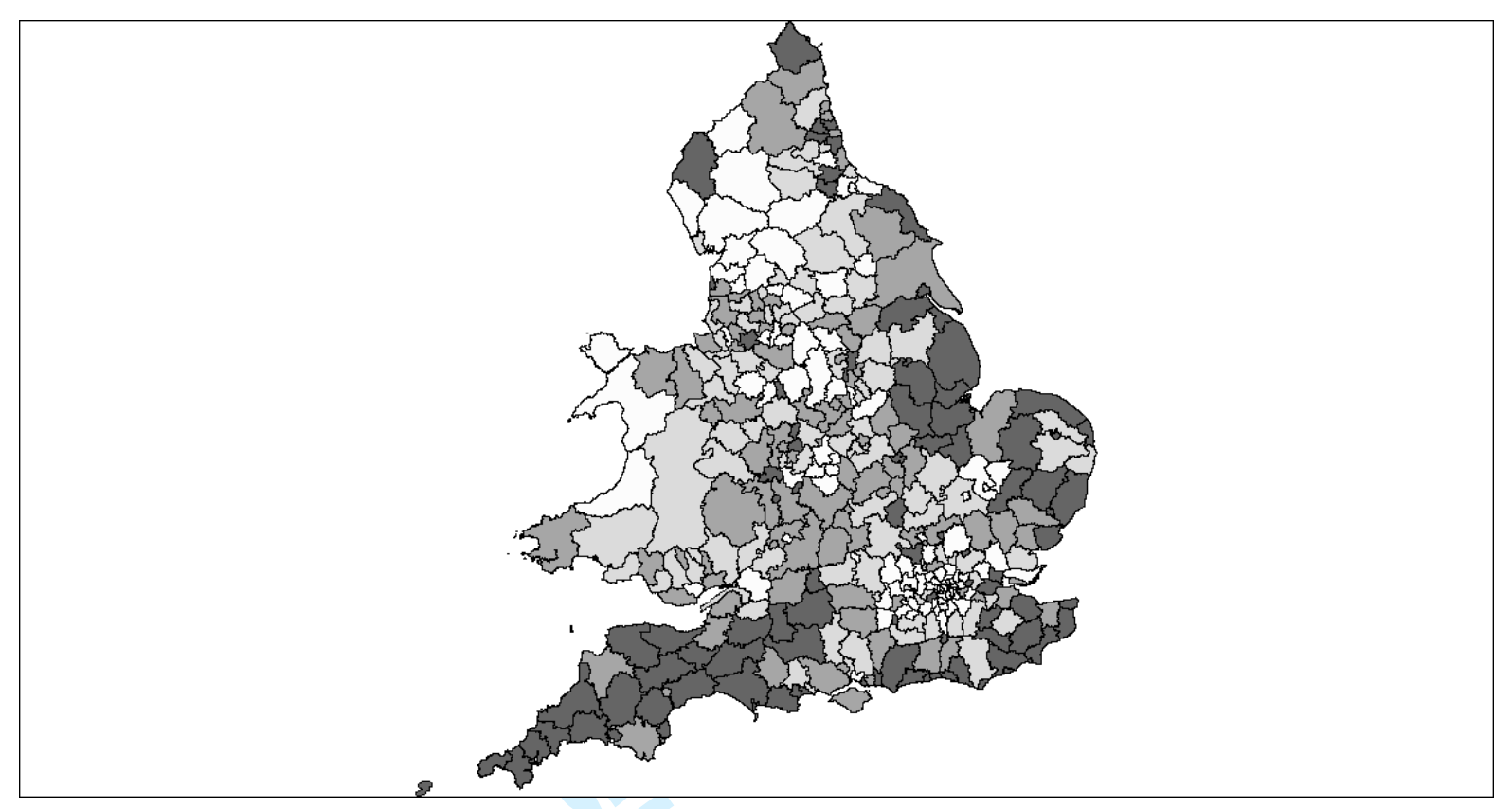

Note: The darkest shaded areas indicate the top quartile through to the lightest areas indicating the lowest quartile. 
Figure 5: LISA clusters 2000

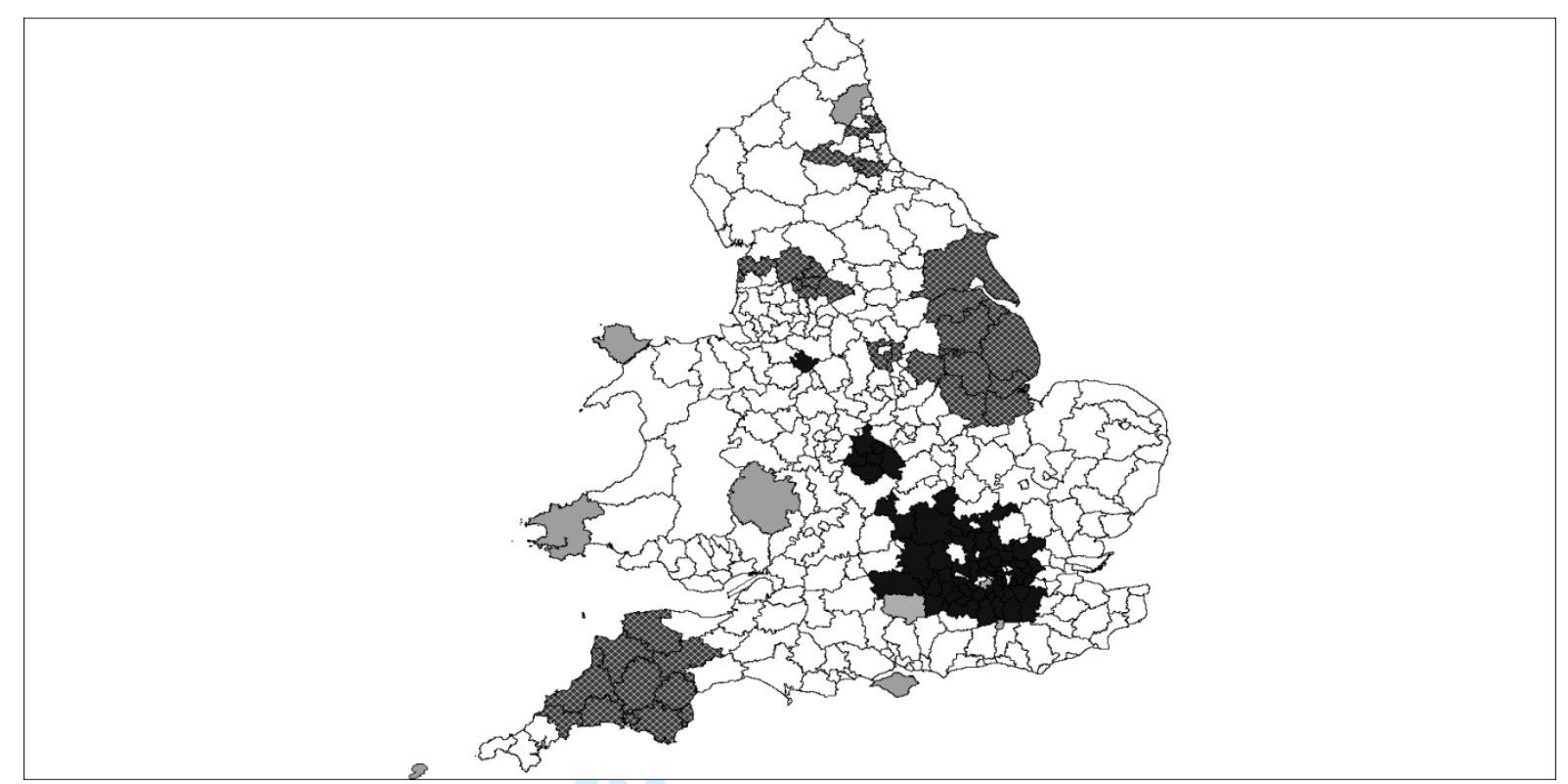

Note: The hatched areas are high-high clusters; the dark shaded areas are low-low clusters; the light shaded areas are outliers. 
Figure 6: LISA clusters 2007

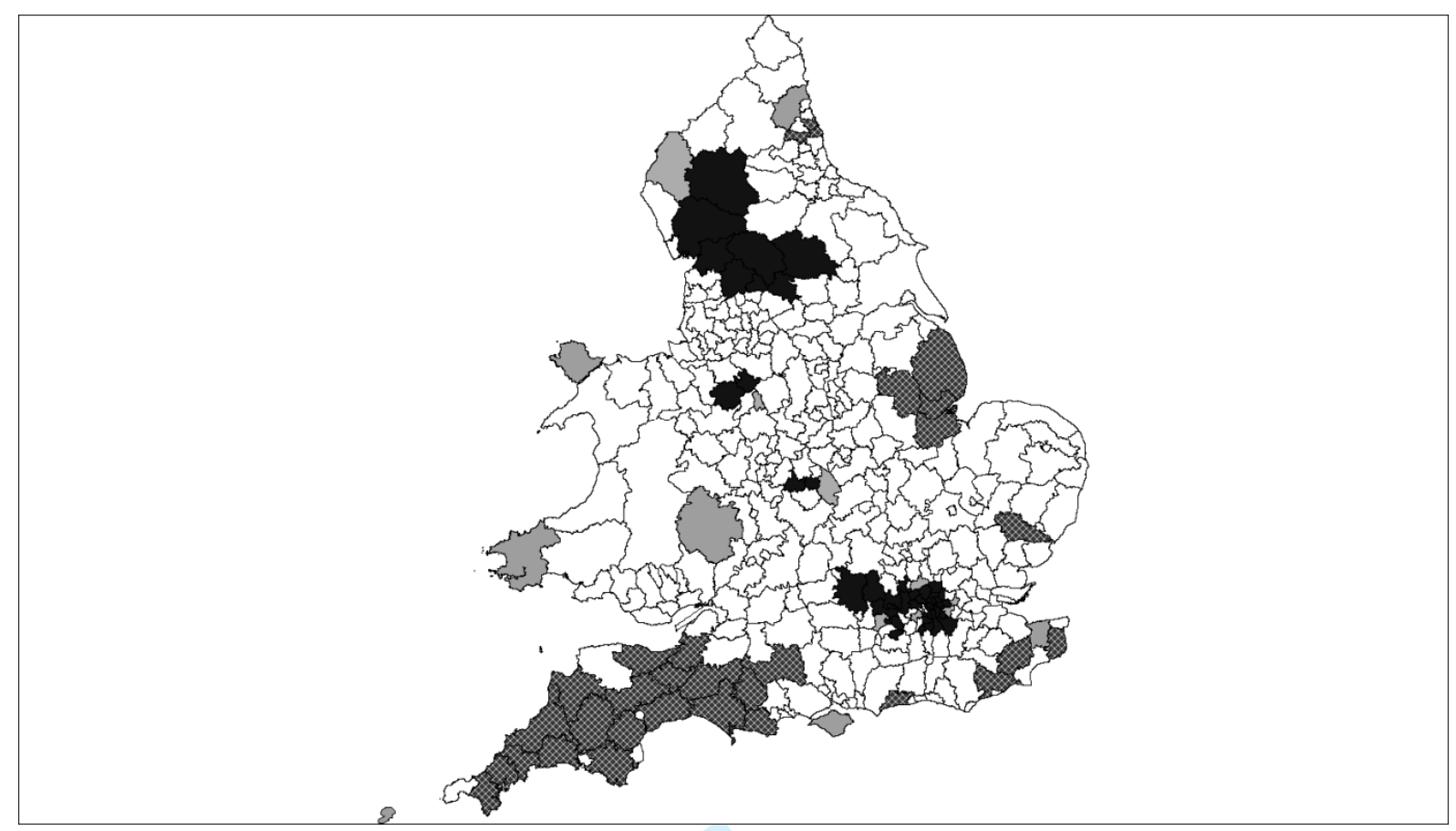

Note: The hatched areas are high-high clusters; the dark shaded areas are low-low clusters; the light shaded areas are outliers. 


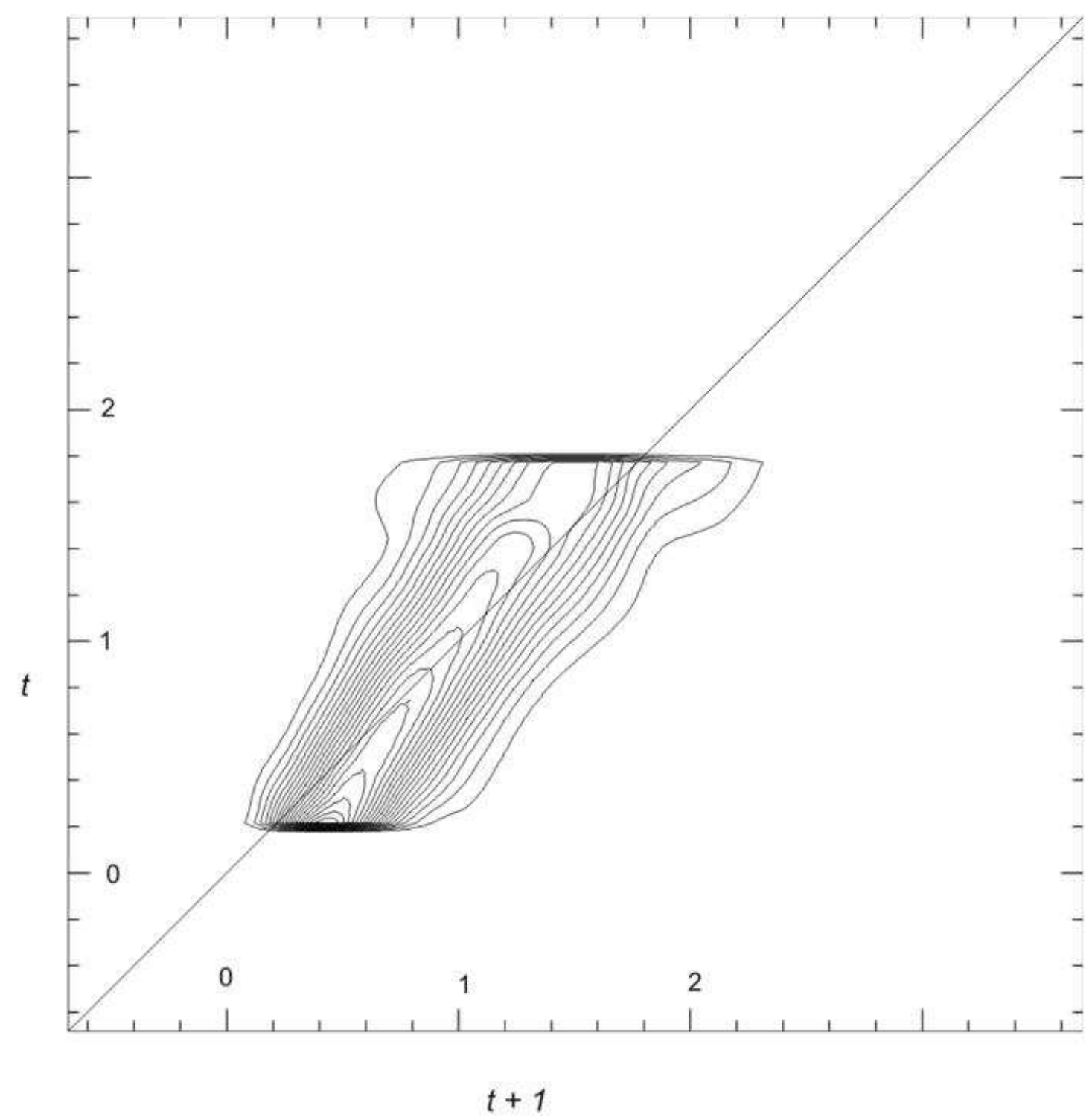

Figure 7: Contour map of stochastic kernel (rates normalised by mean) 
Table 1: Descriptive statistics (sub-regions, per '000 working population)

\begin{tabular}{rrrrrrrrrrr}
\hline & \multicolumn{4}{c}{ Insolvency } & \multicolumn{4}{c}{ Bankruptcy } & \multicolumn{3}{c}{ IVAs } \\
\hline Year & $\mu$ (adj) & $\mu$ & $\sigma$ & $\mathrm{CV}$ & $\mu$ & $\sigma$ & $\mathrm{CV}$ & $\mu$ & $\sigma$ & $\mathrm{CV}$ \\
2000 & 0.950 & 0.841 & 0.288 & 0.342 & 0.621 & 0.233 & 0.375 & 0.220 & 0.102 & 0.464 \\
2001 & 0.968 & 0.881 & 0.330 & 0.374 & 0.703 & 0.287 & 0.408 & 0.179 & 0.088 & 0.492 \\
2002 & 0.983 & 0.907 & 0.326 & 0.360 & 0.726 & 0.285 & 0.393 & 0.182 & 0.088 & 0.484 \\
2003 & 1.135 & 1.063 & 0.365 & 0.343 & 0.843 & 0.337 & 0.400 & 0.220 & 0.091 & 0.414 \\
2004 & 1.470 & 1.384 & 0.433 & 0.313 & 1.074 & 0.397 & 0.370 & 0.310 & 0.113 & 0.365 \\
2005 & 2.140 & 2.046 & 0.615 & 0.301 & 1.434 & 0.538 & 0.375 & 0.612 & 0.198 & 0.324 \\
2006 & 3.354 & 3.235 & 0.834 & 0.258 & 1.900 & 0.652 & 0.343 & 1.335 & 0.349 & 0.261 \\
2007 & 3.324 & 3.230 & 0.830 & 0.257 & 1.947 & 0.636 & 0.327 & 1.283 & 0.342 & 0.267 \\
\hline
\end{tabular}


Table 2: Global Inequality Statistics ${ }^{1}$

\begin{tabular}{ccc}
\hline Year & $\mathrm{T}$ & $\mathrm{G}$ \\
\hline 2000 & 0.057 & 0.189 \\
& $(0.0040)$ & $(0.0064)$ \\
2001 & 0.068 & 0.206 \\
& $(0.0045)$ & $(0.0078)$ \\
2002 & 0.062 & 0.195 \\
& $(0.0053)$ & $(0.0077)$ \\
2003 & 0.056 & 0.185 \\
& $(0.0046)$ & $(0.0075)$ \\
2004 & 0.046 & 0.169 \\
& $(0.0038)$ & $(0.0064)$ \\
2005 & 0.043 & 0.161 \\
& $(0.0036)$ & $(0.0070)$ \\
2006 & 0.032 & 0.139 \\
& $(0.0032)$ & $(0.0057)$ \\
2007 & 0.032 & 0.137 \\
& $(0.0032)$ & $(0.0061)$ \\
$\Delta$ Index & 0.0251 & 0.0512 \\
$95 \%$ CI & $0.0245-0.0257$ & $0.0499-0.0522$ \\
\hline
\end{tabular}

${ }^{1}$ Figures in parenthesis are bootstrap standard errors 
Table 3: Decomposition of Theil by Region

\begin{tabular}{ccccc}
\hline Year & T & Intra-regional & Inter-regional & \% Intra-regional \\
\hline 2000 & 0.057 & 0.044 & 0.013 & 0.772 \\
2001 & 0.068 & 0.049 & 0.019 & 0.721 \\
2002 & 0.062 & 0.047 & 0.015 & 0.758 \\
2003 & 0.056 & 0.046 & 0.010 & 0.821 \\
2004 & 0.046 & 0.035 & 0.012 & 0.761 \\
2005 & 0.043 & 0.029 & 0.014 & 0.674 \\
2006 & 0.032 & 0.023 & 0.009 & 0.719 \\
2007 & 0.032 & 0.025 & 0.006 & 0.781 \\
\hline
\end{tabular}




\begin{tabular}{clcc}
\hline Year & Moran I & $\mu$ & $\sigma$ \\
\hline 2000 & 0.4397 & -0.0028 & 0.0324 \\
2001 & 0.4320 & -0.0016 & 0.0338 \\
2002 & 0.3693 & -0.0003 & 0.0330 \\
2003 & 0.3586 & -0.0038 & 0.0322 \\
2004 & 0.3492 & -0.0025 & 0.0324 \\
2005 & 0.4119 & -0.0008 & 0.0338 \\
2006 & 0.3573 & -0.0026 & 0.0338 \\
2007 & 0.3064 & -0.0033 & 0.0338 \\
\hline
\end{tabular}

Table 4: Moran statistics of spatial autocorrelation $^{1}$

\footnotetext{
${ }^{1}$ All Moran values are significant at the 0.001 level using 999 permutations; $\mu$ and $\sigma$ are the mean and standard deviation of the reference distribution.
} 
Table 5: Transition probability Matrix 2000-07 - one year transitions boundaries held constant ${ }^{1}$

\begin{tabular}{lllll}
\hline State $t$ & \multicolumn{4}{c}{ State $t+1$} \\
\hline Group & $1(0.787)$ & $2(0.959)$ & $3(1.173)$ & $4(2.835)$ \\
1 & 0.65 & 0.25 & 0.09 & 0.01 \\
2 & 0.21 & 0.46 & 0.27 & 0.06 \\
3 & 0.09 & 0.26 & 0.43 & 0.22 \\
4 & 0.02 & 0.06 & 0.21 & 0.71 \\
\hline
\end{tabular}

${ }^{1}$ Figures in brackets give the upper boundaries of each state in terms of the index of insolvencies per capita. 
Table 6: Ergodic Distribution 2000-2007, one year transitions

\begin{tabular}{lll}
\hline $\begin{array}{l}\text { No. of } \\
\text { States }\end{array}$ & $\begin{array}{l}\text { Initial } \\
\text { Class size }\end{array}$ & Ergodic Distribution \\
\hline 4 & 0.250 & $0.232,0.260,0.255,0.253$ \\
5 & 0.200 & $0.283,0.186,0.137,0.166,0.228$ \\
6 & 0.166 & $0.270,0.165,0.144,0.128,0.134,0.158$ \\
7 & 0.143 & $0.195,0.154,0.126,0.102,0.112,0.147,0.165$ \\
8 & 0.125 & $0.181,0.156,0.109,0.109,0.094,0.100,0.111,0.140$ \\
\hline
\end{tabular}


Table 7: Four fractile, time invariant transition probability matrix - one year transitions, varying boundaries

\begin{tabular}{ccccc}
\hline State $t$ & \multicolumn{4}{c}{ State $t+1$} \\
\hline Group & 1 & 2 & 3 & 4 \\
1 & 0.67 & 0.23 & 0.09 & 0.01 \\
2 & 0.22 & 0.45 & 0.27 & 0.06 \\
3 & 0.10 & 0.26 & 0.41 & 0.23 \\
4 & 0.01 & 0.06 & 0.23 & 0.7 \\
\hline
\end{tabular}


Table 8: Mobility Indices 2000-2007

\begin{tabular}{lcc}
\hline Year & $\mathrm{S}$ & $M_{t, t-1}{ }^{2}$ \\
& & \\
\hline $2000-1$ & 0.572 & 0.210 \\
& $(0.0313)$ & $(0.0352)$ \\
$2001-2$ & 0.608 & 0.193 \\
& $(0.0340)$ & $(0.0344)$ \\
$2002-3$ & 0.656 & 0.281 \\
& $(0.0335)$ & $(0.0334)$ \\
$2003-4$ & 0.617 & 0.231 \\
& $(0.0329)$ & $(0.0322)$ \\
$2004-5$ & 0.572 & 0.174 \\
& $(0.0326)$ & $(0.0395)$ \\
$2005-6$ & 0.581 & 0.156 \\
& $(0.0338)$ & $(0.0396)$ \\
$2006-7$ & 0.544 & 0.149 \\
& $(0.0325)$ & $(0.0425)$ \\
\hline
\end{tabular}

${ }^{\mathrm{I}}$ Figures in brackets are standard errors; the $\mathrm{S}$ index is for four fractiles and is asymptotically normal; the $M_{t=t-1}$ errors are bootstrapped.

${ }^{2}$ For this measure, the direction of change in dates is reversed. 